\title{
Teaching Reform of "Supply Chain Management" Based on the Cultivation of Applied Talents
}

\author{
Yuliang $\mathrm{Cao}^{\mathrm{a}}$, Xiuyuan $\mathrm{Li}^{\mathrm{b}}$ \\ College of Business \& Technology, Tianjin University of Technology, Tianjin 300384, China. \\ aylc0081@aliyun.com, ${ }^{\mathrm{b}} \mathrm{m} 13072296330 @ 163 . c o m$.
}

Keywords: supply chain management; applied talents; teaching reform.

\begin{abstract}
Supply chain management (SCM) is the core professional course for cultivating practical talents in logistics management and plays an important role in the teaching system of logistics management. According to the development trend of the industry in recent years and the requirements of the education reform Starting from the student's academic situation, a comprehensive and systematic teaching reform is carried out in three aspects: curriculum objectives, teaching methods, and course assessment methods. in line with the student-oriented and teacher-led teaching concept, the emphasis is to increase the practical link instead of the traditional classroom teaching and adopt a variety of teaching methods and multiple assessment, so as to provide reference for the cultivation of supply chain management applied talents.
\end{abstract}

\section{Introduction}

Supply chain management (SCM) originated in the 1980s and came into being under the background of economic globalization. Supply chain management emphasizes the collaborative planning, organization, coordination and control of cross-enterprise logistics, information flow and capital flow. With the rise of Internet and electronic commerce and the application of RFID technology, the development of supply chain management has provided a broader idea. At the same time, China's logistics and supply chain management began to shift from extensive to lean, from heavy scale to heavy efficiency. The speed of its development is among the highest in the world [1]. With the diversification of demand, we need not only the research talents who study the objective law of things, but also the applied talents who use the objective laws and scientific principles to transform the world so as to create direct benefits for the real life of the masses. The applied talents in supply chain management must begin with the training of colleges and universities. In the teaching of supply chain management in colleges and universities, most of them are taught by theory, and practical teaching involves very little. Therefore, in order to cultivate practical talents of supply chain management, it is necessary for students to master the basic knowledge of supply chain management and to be able to replace some traditional classroom theoretical teaching with practical teaching in combination with the practice of supply chain management in enterprises. Enhancing the embodiment of students' dominant position can also effectively avoid "arbitrariness".

In view of this, the author carries on the comprehensive and systematic teaching reform from four aspects of the course goal, the teaching method and the teaching evaluation method, to increase the classroom vigor of the supply chain management teaching, and to train the high quality applied supply chain management talented person.

\section{Curriculum Objectives}

The curriculum goal is the beginning of the teacher's teaching. The new curriculum standard stipulates that the teaching goal should be systematically designed from the three aspects of "knowledge and skill", "process and method" and "emotional attitude and values". Traditional supply chain management teachers focus on the teaching of theoretical knowledge and the goal setting of "knowledge" in "knowledge and skills", but ignore the goal setting of "skills", "process and methods" and "emotional attitude values". As a major with strong practical application, it needs to define the 
level of students' practical ability from the perspective of curriculum objectives. That is to say, the degree of mastery of professional knowledge required for each course is quantified.

"Process and method goal" is the key goal setting in the teaching of supply chain management curriculum. It mainly includes two aspects: first, understanding the process of subject knowledge formation and development, which is a perceptual cognitive aspect; Second, students can find problems in the process of supply chain management learning, through the interaction between teachers and students as well as using teaching practice to solve practical problems, which are practical aspects.

\section{Teaching Methods}

\subsection{Problems in Current Teaching}

\subsubsection{Lack of Systematic Theory Teaching}

Supply chain management is a series of methods used to effectively integrate suppliers, manufacturers, warehouses and retailers so that the goods produced can be delivered to the right place at the right time and in the right quantity. At the same time, the cost of supply chain can be minimized while meeting the requirements of service level. Teachers often ignore this nature in teaching, unilateral teaching suppliers or manufacturers, and cannot vividly display the knowledge system, so that students cannot clearly understand the theoretical knowledge taught by the teacher. Part of the reason lies in the lack of systematic teaching of theoretical knowledge.

\subsubsection{Pay Attention to the Content of Textbooks, Out of Touch with the Times}

General teachers adopt the combination of textbook knowledge and case teaching, but the problem lies in the fact that most of the cases used by teachers tend to be aging and outdated, which are far from the students' living background and case background, so they cannot achieve the theory close to life. The old cases make it very difficult for students to understand, and the limitations are strong Teachers did not make in-depth analysis of actual background information, development process, and causation, so that students have a sense of distance from the knowledge of supply chain management. Although the teacher occasionally uses multimedia teaching aids to play some videos, due to the lack of the teacher's curriculum introduction or process guidance instructions, the broadcast case is relatively old.

\subsubsection{The Teaching Mode is Single, and the Practicability is Not High.}

The traditional theory teaching mainly uses the case analysis or the multimedia teaching mode, carried on with the pattern of teacher asking questions, the student answering. The study goal also limits in the examination, obtains the credit, causes the student to be lazy to think independently. Independent inquiry, therefore, the subjective enthusiasm of students is difficult to mobilize, and it is difficult to stimulate the enthusiasm and creativity of students to participate [2]. That is to say, theoretical teaching basically follows the traditional "spoon-feeding" teaching. Students have always been in a position of passive acceptance of knowledge and lack of sufficient simulation and practice to support theoretical knowledge. So that students cannot use what they have learned to solve the practical problems of the world. This monotonous teaching model makes students cannot really understand the practicability of supply chain management.

\subsection{Updating of Teaching Methods}

The outline of the National medium and long-term Education Reform and Development Plan 2010 $\sim 2020$ puts forward some specific requirements for the contemporary educators to reform the talent training model. In order to cultivate all-round and multi-level creative talents, it is necessary to replace some traditional classroom teaching with innovative practical teaching. At the same time, we should train applied talents in some fields. The quality of the teaching method determines whether we can achieve the established teaching goals and determines whether we can attract the attention and interest of the students [3]. 


\subsubsection{Task-Driven Case Teaching Method}

The "task-driven" teaching method is based on the constructivism teaching theory. It takes the interesting task as the carrier, stimulates the student's study motive as the goal, and has the close integration degree with the teaching content as the characteristic. It is an inquiry, open teaching model that allows students to acquire knowledge and skills through the completion of a task. The task-driven teaching method highlights the dark line of accomplishing the task and improving the students' knowledge and skill level, and makes the students become the main body. Teachers are the basic characteristics of the organizers [4]. Case teaching means that the teacher collects materials, plans and designs cases according to the teaching objectives, and puts students in a specific situation, through the interaction between teachers and students. Students are guided to conduct in-depth case analysis and extensive discussion and exchange on their own, so as to enhance students' sensitivity to finding problems and to analyze and solve problems clearly. Both of them emphasize student-centered, teacher-led, and emphasize that teaching mode is more open than the traditional model. It pays attention to the active participation of students, independent inquiry and collaborative inquiry, which embodies the characteristics of combining theory and practice teaching.

\subsubsection{Software Training Method}

During the course of supply chain management, we can strengthen students' grasp of supply chain management theory by means of supply chain management software training and so on. In software practice, students are grouped and each member plays a different role in the group. Experience the tasks to be accomplished by different roles, think about the process of achieving goals in the supply chain and the matters to be noted in the process of cooperation. Enterprise management sand table simulation teaching is to allow students to participate in role-playing, to simulate the operation of a practical enterprise. The teaching method covers the real situation of simulating the market competition and cooperation, the interaction and game between enterprises, the micro environment, the macro environment, the formation of the actual decision-making scheme, and even the interpersonal relationship within the enterprise. It can give students the basic understanding of enterprise logistics and supply chain efficiently and intuitively, and further develop and improve the students' systematic thinking ability and related curriculum skills.

\subsubsection{Analog Game Method}

In order to make students better grasp the relevant theoretical knowledge and grasp the essence of the theory, students can be properly organized to carry out simulation games in the course of supply chain teaching. In this course, students can play role, role exchange, complete some such as "beer" game, "prisoner dilemma" game, while experiencing the fun of the game while mastering the nature of supply chain system, integration, cooperation. Students can learn and apply knowledge in a relaxed and pleasant atmosphere, and expand their thinking ability [5].Before simulating the game, the teacher needs to prepare the material and props needed for the course, design the process of the game, ensure the smooth progress of the game and achieve good results, and at the same time, make a good emergency plan for the unexpected events in the classroom, transform unexpected events into teaching resources to reflect the mobility of education.

\subsubsection{Engineering Practice Method}

Engineering practice teaching aims to improve students' employment competitiveness. At present, most colleges and universities focus on engineering practice, which is also one of the teaching reform methods advocated by most colleges and universities. The engineering practice law we say mainly includes two aspects: one is the cooperation of school and enterprise, the regular organization of students into the enterprise, the experience of corporate culture, and the study of how to carry out each link of the supply chain. This kind of close cooperation between school and enterprise can not only help the students to connect the theoretical knowledge to the practice, but also can learn and understand the real operation process of the enterprise, think about the actual problems in the enterprise, and strengthen the ability of using knowledge. Second, the school establishes the corresponding supply chain management laboratory, encourages and instructs the student to carry on the innovation according to the study. It is helpful to realize the integration of "production, learning 
and research". As early as in the 1990s, our country introduced the "production, learning and research" running methods. But because these systems and methods could not adapt to the economic level and education level of the 1990s, it didn't end up in the supply chain management curriculum. Today, our country in the economic development level, the education level, has obtained the sufficient development, has the corresponding condition. We can transform the knowledge into the practice, then transform the engineering practice into the supply chain management productivity.

\section{Course Examination}

The course examination is an important way to test the effect. In the past, the examination mainly focused on attendance and final grade, which could not reflect the students' level of mastering knowledge and applying knowledge. When we reflect on the reform of teaching, we should also consider the way of course assessment, and we should focus on the application of knowledge in the examination of supply chain management courses.

\subsubsection{Diversification of Examination Forms}

The examination form can integrate the traditional attendance, final examination and practice, and divide the grades according to a certain proportion, and make the examination instructions public, so that the students can understand the assessment requirements. This helps to achieve performance differentiation, let the students know their own short board learning. Such as setting attendance score for a total score of $20 \%$, final exam papers accounted for $30 \%$, practice scores accounted for $50 \%$, that will focus on the application of knowledge, rather than knowledge.

\subsubsection{Examination Subject Diversification}

In the past, the main body of teaching assessment is usually teachers. In our teaching reform, we should reflect the diversity of the subject of teaching assessment, adopt teachers and students' mutual evaluation, students' and students' evaluation, and the evaluation of enterprise supervisors in teaching practice. According to the students' learning attitude, the application of the method and the learning effect, teachers should evaluate the students' ability of cooperation and inquiry, and students should also evaluate their cooperation with each other. Students' evaluation should be based on the students' ability of cooperation and inquiry. During the practice period, the enterprise supervisor can also carry on the objective appraisal to the student at a certain stage. Supply chain management course is a multi-subject coordination of the curriculum. The assessment of the main body should also reflect the characteristics of the curriculum. We should pay more attention to formative evaluation and practical assessment.

\section{Conclusion}

In order to meet the learning needs of applied supply chain management personnel, the education of universities has played an important role in promoting the economic and social development of China. The teaching of "supply chain management", especially the course of "supply chain management" in colleges and universities, should be reformed to meet the needs of the times. Only then can the students have the specialty and generality of knowledge, the specialty and development of ability, the generality and discrimination of quality, and thus become the applied talents who can create direct benefits for the society [6]

In order to train application-oriented supply chain management talents, teachers should first change the traditional "spoon-feeding" teaching mode, realize the combination of theory and practice in the teaching process, and provide students with a timely combination of theory with practice and bold practical operation. Get true knowledge in practice, burst out more possibility in practice. This teaching mode is aimed at making the classroom brimming with more vitality, eliciting students' learning passion, allowing students to actively think about problems, using what they have learned to solve problems, and cultivating the spirit of daring to innovate. The course of supply chain management in colleges and universities has truly combined theory with practice: adapting to the present delicate and multi-level teaching environment, it will timely sum up the past and look forward 
to the future development So it. While studying theory, we must also arrange practical lessons or take "professional and business convergence" to consolidate students' learning and develop students' hands-on abilities. This will increase its competitiveness in the talent market [7]. At the same time, the theory and practice of supply chain management are still developing. Only by constantly accepting new things and viewpoints, exploring new teaching methods and methods, can students transform what they have learned into practical working ability in the future. Only then can we achieve the goal of cultivating practical talents in colleges and universities.

\section{References}

[1]. Levy. Supply chain Design and Management: concept, Strategy and case Studies, third Edition [M] .Renmin University Press, 2009.

[2]. Shi Yanhong. Teaching reform of supply Chain Management based on practical teaching [J] .Modern Communication, 20167: 207-207.

[3]. Li Jin-chang, Lin Jia-lian.According to the combination of practical teaching and discipline competition, promoting the cultivation of innovative talents $[\mathrm{J}]$.Experimental Technology and Management, 2011, 2811: 1-3.

[4]. Guo Shaoqing.The connotation of task-driven teaching method [J].Chinese Audio-visual Education, 2006 7: 57-59.

[5]. Xia Cai-yun. Teaching reform of supply chain management course based on vocational ability training [J] .Value Engineering, 2010, 2910: 11-12.

[6]. Song Kehui, Tian Shenghui, Peng Qingwen.Knowledge, ability, quality structure and cultivation of applied talents [J] .higher Education Research: 3307: 94-98.

[7]. Wu Xiaozhi, Zou Huiying, Chen Bensong. A preliminary study on the Teaching reform of applied undergraduate supply chain management [J] .Logistics Engineering and Management, 2017 3904: 188-1898-165. 